\title{
De voces filosóficas en el teatro de Juan Mayorga
}

\section{Erwan Burel}

\section{(2) OpenEdition}

\section{Journals}

Edición electrónica

URL: https://journals.openedition.org/cher/2915

DOI: 10.4000/cher.2915

ISSN: 2803-5992

\section{Editor}

Presses universitaires de Strasbourg

\section{Edición impresa}

Fecha de publicación: 27 junio 2017

Paginación: 109-123

ISBN: 978-2-86820-961-0

ISSN: 1968-035X

\section{Referencia electrónica}

Erwan Burel, «De voces filosóficas en el teatro de Juan Mayorga», reCHERches [En línea], 18 | 2017, Publicado el 01 diciembre 2021, consultado el 21 diciembre 2021. URL: http:// journals.openedition.org/cher/2915 ; DOI: https://doi.org/10.4000/cher.2915

\section{(ब) $\odot \odot$}

Ce(tte) œuvre est mise à disposition selon les termes de la Licence Creative Commons Attribution Pas d'Utilisation Commerciale - Partage dans les Mêmes Conditions 4.0 International. 


\title{
De voces filosóficas en el teatro de Juan Mayorga
}

\author{
ErWan BureL ${ }^{*}$
}

\section{Walter Benjamin como umbral}

Hablar de filosofía cuando abordamos la obra de Juan Mayorga pasa primero por evocar el evidente pero complejo legado benjaminiano en su producción dramática. Doctorado en 1997 en Filosofía, con una tesis titulada La filosofía de la historia de Walter Benjamin ${ }^{1}$, nuestro autor desarrolla un teatro en el que la voz benjaminiana no deja de resonar. Muchos trabajos ya se han publicado en torno al tema ${ }^{2}$ y sería inadecuado repetir aquí lo que ha sido estudiado con tanto esmero. Sin embargo, sí cabe insistir entre las numerosas problemáticas planteadas en los escritos de Walter Benjamin, en la que quizá sea la más importante: la crítica a la idea de progreso y al cumplimiento lineal de la historia. Michael Löwy recuerda que la recepción del pensamiento benjaminiano, particularmente en Francia o en Estados Unidos, se focalizó sobre todo en la vertiente estética, y que el pensador era más bien considerado como un historiador de la cultura o un crítico literario. No obstante, nos dice el estudioso, hace falta evidenciar el alcance mucho más amplio de sus trabajos, y entender que estos apuntaban a una nueva comprensión de la historia humana: «Les écrits sur l'art ou la littérature ne peuvent être compris que par rapport à cette vision d'ensemble qui les illumine de l'intérieur» (Löwy 2003: 199). Los

* Profesor agrégé de español, doctorando y miembro del equipo de investigación CHER (Culture et histoire dans l'espace roman) EA4376 de la Universidad de Estrasburgo.

1 Publicada más tarde y en una versión reducida bajo el título de Revolución conservadora y conservación revolucionaria. Política y memoria en Walter Benjamin (Mayorga 2003).

2 Pensemos en las tesis doctorales de Claire Spooner (Spooner 2013) o Robert March Tortajada (March Tortajada 2014), pero también en la edición crítica de Emilio Peral Vega de las piezas Hamelin y La tortuga de Darwin (Mayorga 2015) o en los trabajos de Gabriela Cordone (Cordone 2011) y Mónica Molanes Rial (Molanes Rial 2014). 
elementos constitutivos de la filosofía de la historia de Benjamin nacen a partir de intuiciones ya perceptibles en sus primeros textos de la década de los años 1910, hasta culminar en las famosas Tesis sobre el concepto de historia de 1940. En ellas, Benjamin opone a la tradición historicista alemana -que escribe la historia desde el punto de vista de los vencedores- otra concepción en la que la historia se escribiría desde el punto de vista de los vencidos:

Il va de soi que le mot "vainqueur" ne fait pas référence aux batailles ou aux guerres habituelles, mais à la "guerre des classes» dans laquelle l'un des camps, la classe dirigeante, «n'a cessé de l'emporter» (Thèse VII) sur les opprimés [...]. L'historicisme s'identifie empathiquement (Einfühlung) aux classes dominantes. Il voit l'histoire comme une succession glorieuse de hauts faits politiques et militaires. En faisant l'éloge des dirigeants et en leur rendant hommage, il leur confère le statut d' «héritiers » de l'histoire passée. En d'autres termes, il participe - comme ces personnages qui élèvent la couronne de lauriers au-dessus de la tête du vainqueur - à ce «cortège triomphal où les maîtres d'aujourd'hui marchent sur les corps des vaincus» (Thèse VII) ${ }^{3}$. (Löwy 2003: 203)

Bien vemos cómo Benjamin se apoya en una consideración marxista de la historia, reutilizando para su propio pensamiento el tema de la lucha de clases. Pero se trata de un marxismo peculiar, puesto que subvierte la idea misma de progreso. Efectivamente, Benjamin no considera el progreso sin la catástrofe. El séquito triunfal de los vencedores no es sino una serie de catástrofes para los vencidos. En este sentido, resulta imposible desvincular estas Tesis del contexto histórico en el que Benjamin las escribe. Su filosofía de la historia debe permitir entender el fascismo no como una excepción en la vía del progeso, sino como el revés de una misma moneda: «Le fascisme porte à ses dernières conséquences la combinaison typiquement moderne entre progrès technique et régression sociale» (Löwy, 2003: 204). Detrás de esta crítica al progreso, Benjamin desarrolla en realidad una crítica al tiempo histórico considerado como lineal y homogéneo. Para él, la historia desde el punto de vista de los vencidos apela a una concepción del tiempo rompedora y revolucionaria -o mesiánica-:

Contre cette vision linéaire et quantitative, Benjamin oppose une perception qualitative de la temporalité, fondée d'une part sur la remémoration, de l'autre sur la rupture messianique/révolutionnaire de la continuité. La révolution est le «correspondant» (au sens baudelairien du mot) profane de l'interruption messianique de l'histoire, de l'«arrêt messianique du devenir» (Thèse XVII): les classes révolutionnaires, écrit la Thèse $\mathrm{XV}$, sont conscientes, au moment de leur action, de "briser le continuum de l'histoire». L'interruption révolutionnaire est donc la réponse de Benjamin aux menaces que fait peser sur l'espèce humaine la poursuite de la tempête maléfique qu'on appelle «Progrès», une tempête qui accumule ruine sur ruine et prépare des catastrophes nouvelles (Thèse XII). C'était l'année 1940, peu avant Auschwitz et Hiroshima... (Löwy 2003: 204)

3 Michael Löwy precisa que las citas de las Tesis sobre el concepto de historia proceden de la traducción de Maurice de Gandillac en Poésie et révolution (Benjamin 1971). 
Esta concepción benjaminiana del tiempo y de la historia aparece claramente en el teatro de Juan Mayorga. Su teatro, como él mismo lo suele repetir, intenta hacer visible la ausencia de los oprimidos y hacer que resuene el silencio de los olvidados. Este afán de recuperación de la memoria histórica pasa por distintos recursos, y en particular por el recurso a una teatralidad elíptica (por «elíptica», nos referimos tanto a la elipsis, figura retórica, como a la elipse, figura geométrica). En Himmelweg por ejemplo, pieza que dramatiza la visita de un Delegado de la Cruz Roja a un campo de concentración y la mascarada organizada por el Comandante nazi ${ }^{4}$, las rupturas y los silencios en los diálogos de los personajes, así como las elipsis temporales y espaciales a lo largo de la pieza, configuran una ficción teatral no lineal en la que el espectador se ve implicado. Son estas rupturas y omisiones las que, paradójicamente, dan a ver la ausencia de las víctimas de la Shoah y hacen oíble su silencio. Esa teatralidad elíptica incita -esperemos- al espectador a recuperar y preservar una memoria que siempre presenta el riesgo de ser engullida por la cultura dominante. Esto lo comprobamos con la fuerte dimensión narrativa de la pieza (que consta de dos largos monólogos) asumida exclusivamente por los dos personajes dominantes (el Delegado de la Cruz Roja y el Comandante del campo). Efectivamente, estos personajes son los únicos, al pronunciar cada uno un monólogo, en romper la cuarta pared (se dirigen varias veces a un auditorio evidentemente ficticio pero que se confunde con la asamblea de espectadores). Dicho de otra manera, son estos personajes los que tienen la posibilidad de interpelar al público en el hic et nunc de la representación. Sin embargo, respecto a la propia vivencia de las víctimas puesta en escena en las otras secuencias de la pieza, estos personajes dominantes se ven desacreditados (el Delegado no supo o no quiso ver el horror detrás de la farsa y el Comandante fue quien la organizó). Entonces entendemos que la verdad no procede del discurso de la autoridad (El Comandante) o de las Instituciones (el Delegado), sino de la comparación de la vivencia de las víctimas con este discurso. Así es como Juan Mayorga, mediante el prisma del pensamiento benjaminiano, intenta hacernos ver más allá del discurso de la cultura dominante con el fin de recuperar la memoria de los oprimidos. El recurso a una teatralidad elíptica funciona también en otra pieza, El Cartógrafo. Esta obra cuenta la historia de un viejo cartógrafo judío que manda a su nieta a dibujar el gueto de Varsovia. De manera paralela, dramatiza también el recorrido de otro personaje femenino, en una Varsovia contemporánea, en

4 Para Himmelweg, Mayorga se inspiró en la película de Claude Lanzmann, Un vivant qui passe de 1997, entrevista que Maurice Rossel le había concedido al director de cine en 1979 y que debía ser incluida en la película Shoah, de 1985. Maurice Rossel, delegado de la Cruz Roja, había sido mandado a visitar los campos alemanes durante la segunda guerra mundial. Se fue a Auschwitz en 1943 y al campo de Theresienstadt en junio de 1944. Durante esta visita, le engañaron los nazis al montar una mascarada para esconderle el horror de la vida en el gueto. Maurice Rossel se lo creyó (o fingió creérselo) e hizo un informe positivo de su visita. En Himmelweg, Mayorga dramatiza la fase de preparación de esta mascarada y la visita del delegado. 
busca de ese mapa que se ha convertido con el tiempo en una verdadera leyenda. La teatralidad elíptica funciona de manera mucho más explícita ya que la elipse construye, geométricamente hablando, el espacio. Mayorga intenta con esta pieza hacer que aparezca en el escenario lo que él llama, siguiendo a Benjamin, una imagen dialéctica. Una imagen nacida de la asociación entre dos objetos distantes que, considerados juntos, abren un campo inédito de reflexión. El dramaturgo da las claves para entender esta idea en un texto donde analiza el pensamiento benjaminiano precisamente según el modelo de la elipse como figura geométrica:

La imagen de la elipse es útil para entender el modo en que lee Benjamin y, me parece, debería ser tenida en cuenta para leer al propio Benjamin. Quien con frecuencia desencadena su pensar al descubrir la conexión -que nunca es identificación, sino vínculo atravesado de tensiones- de dos motivos distantes que al asociarse abren un campo de preguntas. Así procede, por ejemplo, en el libro sobre el Trauerspiel, la investigación del cual hace depender de la búsqueda de accesos no directos al objeto y del rodeo de este como método -observar el objeto como foco de una elipse es, por cierto, rodearlo de un modo más productivo que trazando a su alrededor una circunferencia, en que los puntos de vista a ocupar son equidistantes de la cosa observada-. También en su tenaz trabajo como paseante: Benjamin camina siempre como un lector doble, que en cada rincón de la ciudad ve dos ciudades, la hoy dominante y esa otra de la que no hay sino huellas fugaces. Y, desde luego, en Sobre el concepto de historia, que se despliega alrededor del par materialismo histórico / teología. (Mayorga 2010a).

De la misma manera, en El Cartógrafo Mayorga enfrenta en el escenario dos focos, dos momentos de una ciudad que, si no estuvieran puestos juntos, no nos revelarían cuanto nos pueden revelar. La Varsovia contemporánea borró casi todas las huellas de un pasado que sin embargo es digno de respeto y memoria. $\mathrm{Y}$ es solo al citar -y la cita es un procedimiento típicamente benjaminiano ${ }^{5}$ el pasado desde nuestro presente, es decir la Varsovia del gueto desde la Varsovia actual o, incluso, desde el hic et nunc de la propia representación teatral, cómo podamos recuperar la memoria de los oprimidos. Al igual que en Himmelweg, Mayorga construye una ficción teatral no lineal en la que el espectador se ve implicado. Lo que es mostrado en el escenario tiene que ser reconstruido. El teatro es como un mapa, es una perspectiva peculiar sobre la realidad que invita al espectador a descifrarla.

En el caso del teatro de Mayorga, esta perspectiva peculiar se focaliza especialmente en la violencia de nuestra modernidad. Sabemos que los siglos xIX y xx pusieron en duda la idea de razón como oposición a la violencia, mostrando que se trata de una de sus propias modalidades. Benjamin, heredero del romanticismo alemán, se inscribe en esta crítica de la razón al desmontar el mito del progreso. En este sentido, su filosofía de la historia es también una

5 Todo el pensamiento benjaminiano se desarrolla bajo la forma del ensayo, del fragmento e incluso de la cita. Por eso siempre resulta difícil hablar de sistema filosófico para Benjamin (Löwy 2003: 199). 
reflexión en torno a la violencia, reflexión que ya había empezado anteriormente con su Critique de la violence (Benjamin 2000a: 210-243). Podemos citar al respecto que:

Walter Benjamin ne s'est pas intéressé aux manifestations psychologiques et sociologiques de la violence. Si celle-ci constitue pour lui un objet philosophique, c'est d'abord en tant que force liée originellement au droit dont elle assure la fondation et la préservation sous le nom de violence d'État, mais aussi en tant qu'éclatement brutal des enchaînements historiques et surgissement catastrophique d'une nouvelle ère, dans laquelle les uns veulent reconnaître la Grande Révolution, tandis que les autres y voient plutôt la restauration utopiste d'un paradis perdu. Pour Benjamin, la notion de violence relève donc autant de la philosophie politique que d'une philosophie de l'histoire se situant aux confins de la métaphysique et de la théologie. (Collomb 2011: 141)

El prisma del pensamiento benjaminiano en el teatro de nuestro autor nos encamina hacia la temática de la violencia. Una temática que se puede estudiar desde varios ámbitos. El del poder y la historia, como nos indica la cita anterior, con piezas por ejemplo como La paz perpetua (sobre el terrorismo y la violencia de Estado), Siete hombres buenos y El jardín quemado (sobre la guerra civil), Cartas de amor a Stalin (sobre la censura estalinista), La tortuga de Darwin (sobre la concepción de la historia), etc. Pero también desde otros ámbitos como la violencia social, familiar, interpersonal, del grupo o de la comunidad (con obras como Hamelin, El gordo y el flaco, El chico de la útlima fila, etc.), o la violencia y su relación con el mal (con obras como Himmelweg, Job, Animales nocturnos y Palabra de perro $)^{6}$. Por cuestiones evidentes de espacio, nos limitaremos a tratar este último aspecto en la producción dramatica de Mayorga.

\section{De la radicalidad a la banalidad del mal (Himmelweg)}

La dramaturgia mayorguiana, al abordar temáticas como la Shoah, la guerra civil española, la inmigración, la censura estalinista, la pederastia, el terrorismo, la guerra fría, etc., se interroga sobre la violencia y el mal, particularmente en la época actual donde las lógicas perversas que prevalecieron durante la segunda guerra mundial son susceptibles de reaparecer en cualquier momento.

¿Será el mal una sustancia, incluso una esencia, fundamentalmente opuesta al bien, lo que haría de nosotros seres buenos o malos, o estará el mal vinculado al bien, de tal suerte que la posibilidad del mal exista para cada uno de nosotros? Toda la filosofía, desde Platón hasta los pensadores contemporáneos, es atravesada por esta pregunta. Para Platón, la verdad es el equivalente del bien. El hombre es malo porque es ignorante. Solo el conocimiento lo puede acercar a la verdad y, entonces, al bien. Desde Platón, la filosofía ha

6 Queda claro que esta división en grupos es puramente práctica. En realidad, cada pieza está atravesada por una multitud de aspectos relacionados con el concepto de violencia. 
elaborado otras concepciones del mal y queda obvio que los pensamientos contemporáneos, después de Auschwitz, ya no pueden aceptar tal concepción del mal. El conocimiento no hace de nosotros seres absolutamente buenos. El mal no se yergue ante nosotros, tapándonos el acceso a la verdad, sino que es muy probablemente una virtualidad inscrita en cada uno de nosotros.

San Agustín rechazó la enseñanza de los maniqueos al afirmar que el mal no era una sustancia en sí, que lucha contra la otra sustancia del bien, sino una deviación de la propia voluntad que se aparta de Dios. Hannah Arendt -que dedicó su tesis doctoral al pensamiento agustiniano- se niega a pensar el mal como radical, encarnado por ciertas figuras del nazismo, y desarrolla su famoso concepto de banalidad del mal. Este concepto, bien se sabe, provocó mucha polémica (basada a menudo sobre interpretaciones erróneas), pero hay que reconocer que cambió definitivamente nuestra comprensión del mal.

Antes de llegar al concepto de banalidad del mal, Arendt hablaba, a semejanza de Kant, de mal «radical» cuando analizaba los campos de concentración y el totalitarismo en Le système totalitaire (Arendt 1972). Con su Eichmann à Jerusalem (Arendt 2002), deja de lado este concepto por el de banalidad del mal. Pero hay que precisar que «banalidad del mal»y «mal radical» son más cercanos de lo que parece:

Il semble bien qu'Arendt ait manqué la portée de l'analyse de Kant et qu'elle en ait méconnu les implications. En effet, chez Kant, le mal radical n'a rien à voir avec une soi-disant "profondeur», avec la psychologie individuelle ou collective, avec l'enracinement intellectuel ou idéologique, ni avec la présence de telle ou telle motivation. Le mal radical, qui est celui de l'espèce, renvoie au pouvoir originaire d'une liberté susceptible de s'orienter vers le bien ou vers le mal. [...] On voit déjà en quel sens ce mal radical, étranger à toute "profondeur», peut être qualifié de «banal»: il est radical parce qu'il est banal. Il est le mal de tous même si tous ne le font pas. (Revault D’Allones 2011: 834)

Lo que Arendt afirma en su hipótesis de la existencia de una «banalidad del mal» no es muy distinto. Al asistir, como corresponsal para la revista The New Yorker, al juicio de Adolf Eichmann en Jerusalén en 1961, da cuenta en sus artículos de un hombre ordinario. Lejos de ser un monstruo sanguinario con motivos oscuros, ve a Eichmann como el prototipo del sistema totalitario. Se trata de un hombre cuya mediocridad es patente y que carece de profundidad y de raíces ideológicas contundentes. Es un burócrata banal que se aleja de la figura demoníaca con la cual algunos quisieran identificar los fundamentos del mal. Al apartar a Eichmann de la monstruosidad y al incluirlo en una humanidad ordinaria, Arendt no banaliza ni disminuye el horror del funcionario nazi. Al contrario, plantea el problema de una «normalidad» de los criminales y de un mal extremo que puede ser cometido por cualquier hombre. Resalta entonces un punto esencial de su reflexión que está en el centro de su concepto de banalidad del mal: la derrota del pensamiento. Para Arendt, la figura del mal no existe y cada cual, si deja de pensar, si deja de gobernar su voluntad por el pensar, puede abrazar el mal extremo como ocurrió en el siglo xx. 
La obra Himmelweg convoca inevitablemente el pensamiento de Hannah Arendt con personajes como el Delegado o el Comandante del campo, personas ordinarias e incluso cultas -en el caso sobre todo del Comandante- que participan, conscientemente o no, en la barbarie. Pero la obra de Juan Mayorga también pone en escena a otro personaje, Gottfried -un judío que se ve obligado a organizar, con el Comandante, la mascarada-, lo que (re)plantea la cuestión de la responsabilidad de los judíos en su propia exterminación. Y fue precisamente esta cuestión la que desató la polémica en torno al Eichmann en Jerusalén de Hannah Arendt.

Con la evocación de los Consejos judíos (Judenräte), la filósofa señalaba uno de los puntos más delicados del III ${ }^{\text {er }}$ Reich: la colaboración de algunos judíos en el exterminio puesto en marcha por los nazis. Los Judenräte fueron pensados como entidades dirigidas por responsables judíos para establecer la relación entre las autoridades alemanas y los propios judíos. Arendt sostenía que si esas organizaciones no hubieran existido, el número de víctimas entre el pueblo judío hubiera sido menor. Con esta afirmación, no condenaba jurídicamente a los responsables judíos que cooperaron con los nazis, ya que se sabe que esta cooperación fue evidentemente forzada. Lo que hacía era cuestionar la responsabilidad de esos capos judíos en un ámbito no jurídico, sino político y moral. Lo hacía además señalando que, de hecho, existieron algunos casos de resistencia, en particular en Dinamarca ${ }^{7}$, donde los responsables judíos se habían negado a cooperar y habían informado a la gente de su comunidad.

El pensamiento de Arendt nos da a entender la importancia que supone la Shoah en nuestra aprehensión de la modernidad. Bajo la fórmula tan criticada de «banalidad del mal», se esconde en realidad uno de los pensamientos más complejos y sutiles del siglo xx. Un pensamiento que plantea el problema de nuestra pertenencia a una especie que puede cometer el mal extremo, y esto no solo en el contexto nazi sino también en el contexto post-Auschwitz en el que vivimos. Con Himmelweg, Mayorga se inscribe sin dificultad en esta senda arendtiana y lo que subyace en realidad en esta pieza es la interrogación en cuanto a nuestra capacidad de resistir ante tal cumplimiento del mal.

\section{Aporía del mal y sufrimiento (Job)}

Otras obras de Juan Mayorga interrogan la noción del mal y de la violencia como por ejemplo Job, en la que nuestro autor trata del sufrimiento y de la fe. Esta pieza se inspira explícitamente en el consabido Libro de Job y en otros tres relatos de personas que pasaron por los campos nazis: La nuit de Elie Wiesel, Yossel Rakover s'adresse à Dieu de Zvi Kolitz y Une vie bouleversée. Journal 1941-1943 de Etty Hillesum. El mal extremo que cae encima de Job queda destacado (y a la inversa) por los relatos de los testigos de los campos de concentración. Cada relato es asumido por uno o varios personajes, entre los cuales está el personaje

7 Cf. Arendt (2002: 309-318). 
del Narrador que atraviesa toda la obra. La dimensión narrativa es esencial y hace de esta pieza una verdadera composición de voces:

El punto de partida es un oratorio compuesto por el dramaturgo Juan Mayorga con textos tomados del Libro de Job y de tres supervivientes de los campos de exterminio en los que el sufrimiento de los inocentes se hace preguntas tales como ¿dónde está Dios?, ¿dónde está el hombre?, ¿es posible hablar de la justicia de espaldas al sufrimiento del hombre?, ¿cuál es el lugar de la compasión política? Los testimonios que se aportan en esta obra son estremecedores, y su talante ético es admirable frente a la injusticia y a las indebidas penalidades de su vida. (Mayorga: 2004) ${ }^{8}$

Paul Ricoeur, en Le mal. Un défi à la philosophie et à la théologie (Ricœur: 2004), afirmaba que se debe renunciar a la pregunta del «¿Por qué el mal?» y admitir la inciencia (la imposibilidad de conocer) del origen del mal:

Le mal, c'est ce contre quoi on lutte, quand on a renoncé à l'expliquer. Or, il faut avouer que le prix à payer est plus élevé qu'on ne le suppose: le mal est rencontré comme une donnée inexplicable, comme un fait brut [...] Il y a le mal. Mais je ne sais dire pourquoi. Un tel aveu d'inscience me parait avoir une valeur libératrice considérable. (Ricœur 2005: 107-108)

Si renunciamos al origen del mal, tenemos entonces que orientar nuestro pensamiento hacia el futuro. Nuestro pensamiento tiene que ir hacia adelante y mantener el mal en una dimensión práctica. Nuestra relación con el mal es una relación del "contra», el mal es aquello contra lo que luchamos. En esta perspectiva orientada hacia el porvenir, Ricoeur nos dice además que el mal es una categoría del «a pesar de», es el riesgo de la fe, el riesgo que corre cada creyente al creer a pesar de todos los males que experimenta. Pero el filósofo va más allá y desarrolla lo que llama una sabiduría personal. Alude a una sabiduría que supuestamente permitiría superar el «contra» o el «a pesar de» y aceptar finalmente el mal tal y como es. Dicho de otra manera, esta sabiduría nos permitiría adoptar una postura de renunciamiento ante lo que el mal apela y provoca en nosotros. Y esta experiencia de renunciamiento, Ricoeur la encuentra precisamente en el Libro de Job:

J'ose suggérer que ce mouvement de la pensée et du cœur est peut-être celui qu'accomplit le Livre de Job dans sa conclusion. Car, de quoi Job, supposé juste, se repentirait-il, sinon uniquement de s'être plaint? Alors, mais alors seulement, on comprend en quel sens il peut être dit de Job qu'il est arrivé à aimer Dieu "pour rien», faisant ainsi perdre au Satan du conte populaire son pari initial... Aimer Dieu pour rien, c'est sortir complètement du cycle de la rétribution, dont la lamentation reste encore captive, tant que je me plains de l'injustice de mon

8 Se trata de un fragmento de la contraportada del libro mencionado.

9 Podemos encontrar una versión resumida de esta reflexión en una intervención de Paul Ricoeur durante un debate con Bernard Dupuy, Emmanuel Levinas, Elisabeth de Fontenay et Jean Halpérin, sobre «Le scandale du mal». Esta intervención fue publicada por primera vez en Les Nouveaux Cahiers ( ${ }^{\circ} 85$, été 1986) y en la revista Esprit en 1988 y en 2005 (Ricœur 2005). 
sort. Peut-être est-ce là l'ultime réponse au «problème» du mal: atteindre le point de renoncement au désir, au désir même dont la blessure engendre la plainte; renoncement au désir d'être récompensé pour ses vertus; renoncement au désir d'être épargné par la souffrance [...] (Ricœur 2005: 110-111)

El pensamiento de Ricoeur en torno al mal y al sufrimiento ${ }^{10}$ echa una luz extraordinaria sobre el Libro de Job y la obra de Juan Mayorga. Además, al entremezclar varios discursos sobre la fe y la existencia del mal, la pieza de nuestro autor remite también a otro pensador imprescindible para comprender el mundo post-Auschwitz donde Dios parece haber abandonado a los hombres: nos referimos a Hans Jonas en Le concept de Dieu après Auschwitz (Jonas 1994). El filósofo, con el fin de mostrar que la barbarie nazi no aniquila la fe sino que nos incita a construir otro concepto de Dios, desarrolla lo que llama un concepto «débil» de Dios. Niega así la omnipotencia que le solemos atribuir para decir que en Auschwitz, Dios -contrariamente a aquellos que afirmaban que allí había escondido su cara- no podía intervenir. Jonas nos habla de un Dios que, en el acto de creación, se ha autolimitado. A partir del momento en que el hombre fue creado, la suerte de este no dependió más de Dios sino que, a la inversa, fue la suerte de Dios la que dependió del hombre. En el acto de creación, Dios se ha despojado de su potencia al conceder a los hombres la libertad y el conocimiento del bien y el mal. En Auschwitz, no fue Dios quien abandonó a los hombres, sino los hombres quienes abandonaron a Dios ${ }^{11}$ :

Renonçant à sa propre invulnérabilité, le fondement éternel a permis au monde d'être. Toute créature doit son existence à cette négation et a reçu avec cette existence ce qu'il y avait à recevoir de l'au-delà. Dieu, après s'être entièrement donné dans le monde en devenir, n'a plus rien à offrir : c'est maintenant à l'homme de lui donner. Et il peut le faire en veillant à ce que, dans les cheminements de sa vie, n'arrive pas, ou n'arrive pas trop souvent, et pas à cause de lui, l'homme, que Dieu puisse regretter d'avoir laissé devenir le monde. (Jonas 1994: 38-39)

Además, comprobamos que Jonas habla también de renunciamiento $y$, de alguna manera, se acerca al pensamiento de Ricoeur. Efectivamente, Jonas habla de renunciar al concepto que le concede a Dios la potencia de intervenir en el mundo e impedir la barbarie humana. Se trata finalmente de una postura de renunciamiento en cuanto a la creencia en un Dios que pueda salvar a su criatura del mal. Son los propios hombres quienes tienen que salvarse del mal y de la violencia. Son ellos quienes deben intentarlo todo para no decepcionar y no hacer sufrir a su creador. No hacer sufrir a Dios y ayudarle antes que esperar a que él nos ayude pasa evidentemente por no hacer sufrir al prójimo. Auschwitz

10 La tesis se presenta aquí de modo muy esquemático y se recomienda la lectura pronfundizada de Le mal. Un défi à la philosophie et à la théologie (Ricœur 2004).

11 Otra vez, el pensamiento del filósofo está muy resumido aquí. Se recomienda la lectura de Le concept de Dieu après Auschwitz, así como el excelente artículo de Robert Theis, «Dieu éclaté. Hans Jonas et les dimensions d'une théologie philosophique après Auschwitz» (Theis 2000). 
nos obliga no solo, nos dice Jonas, a pensar otro concepto de Dios, sino también a hacernos responsable de la humanidad:

C'est face à l'accusation possible des générations futures, face au fait qu'elles puissent nous rendre responsables d'avoir été de mauvais gérants et, au cas extrême, face à l'absence d'accusation du fait de la non-existence pure et simple de générations futures, qui serait en fait la pire des accusations à notre égard, que nous incombe le devoir de veiller à ce qu'il y ait un avenir de l'homme. "Qu'il y ait une humanité» ${ }^{12}$, voilà l'impératif de l'éthique de la responsabilité. (Theis 2000: 355)

Emmanuel Levinas es otro filósofo que, después de Auschwitz, se esforzó por pensar de nuevo el problema del mal, y esta vez en relación con la cuestión del otro y de la epifanía del rostro. Con un lenguaje cuyos términos proceden en gran parte de lo religioso, la reflexión de Levinas -que sin embargo no es un discurso teológico- se inscribe en una voluntad de rehabilitar una humanidad en la que existe un altísimo grado de violencia.

\section{El mal y el otro (Animales nocturnos y Palabra de perro)}

Desde mucho tiempo, la filosofía intenta combatir la violencia por el logos, por el uso de un discurso razonado. Se trata de uno de sus objetivos fundamentales y humanistas que, a pesar de la larga serie de violencias sufridas por los humanos, parece resistir. En este sentido, la filosofía de Levinas, después de la experiencia de la Shoah, podría considerarse como el intento de establecer un nuevo humanismo, pero un humanismo basado en una ética ya no construida a partir del logos sino de aquello que el rostro ajeno apela en nosotros:

Parler à quelqu'un rompt la violence de la solitude, fût-elle méditante, car nul ne peut parler en vérité s'il n'écoute, s'il n'a reconnu en autrui un interlocuteur et s'il n'a regardé son visage. Or le visage, contrairement aux choses qui offrent une prise, se dérobe à toute mainmise, fût-elle théorique. On peut vouloir s'en saisir et l'avilir, on peut certes le violenter et le tuer réellement, mais on n'échappe pas ainsi à la parole qu'il fait entendre: "Tu ne tueras pas.» C'est précisément cette parole qui constitue la résistance éthique du visage que Levinas oppose à la violence car, selon lui, c'est elle - et non le logos - qui constitue le principe de tous les discours et de la spiritualité. Cette parole ouvre un espace de non-retour à soi-même, elle arrache à sa solitude car, devant autrui, chacun s'entend à «ne pas exister violemment et naturellement" mais à parler, à s'adresser à lui, à lui répondre, à céder la première place, sa place de solitaire et de souverain. (Chalier 2011: 811)

El hombre violento es aquel que se niega a recibir esta palabra prescriptiva del rostro ajeno. El hombre violento es aquel que no sale de sí mismo, que vuelve constantemente a sí mismo, negando la libertad y alteridad del otro. Levinas precisa que esa palabra prescriptiva del rostro ajeno no basta para luchar moralmente contra la violencia y que, desde luego, la ley y un orden político

12 Robert Theis cita a Hans Jonas en su libro Le principe responsabilité (Jonas 2013). 
justo son necesarios para prevenir la acción del hombre violento o tiránico. Pero la fuerza de tal prescripción procedente del rostro del otro, según Levinas, reside en su carácter transcendental o infinito:

À sa façon, cette parole est encore celle d'un maître mais d'un maître foncièrement différent du tyran qui aliène les autres à sa cause car ce maître là, dans sa vulnérabilité extrême, et sans qu'il le sache lui-même, interdit moralement ce qu'il n'a pas la capacité réelle d'empêcher. Dans sa hauteur et dans sa faiblesse, ce maître, ou encore ce visage, enseigne la force d'un commandement qui oriente autrement dans l'être. Mais il ne le fait pas en son nom propre ou pour défendre lui-même son droit à la vie: c'est parce qu'il se trouve dans la trace de l'Infini, dans la trace du Dieu invisible et inimaginable, du Dieu irréductible à toute présence, consolante ou intimidante, qu'il témoigne de cette parole immémoriale qui enjoint non seulement à laisser vivre, mais à faire vivre. (Chalier 2011: 813)

Para el filósofo, el mandamiento "No matarás» del rostro ajeno es la señal de su presencia infinita, de su transcendencia, o por lo menos de aquella de la que testimonia por hallarse en la senda de Dios. Y el punto crucial del pensamiento levinasiano es que este mismo mandamiento es, él también, violencia. La alteridad, para Levinas, es una alteridad que obliga. La ética del rostro ajeno exige que uno se haga responsable de su prójimo. Ya no ser el rival de su hermano sino su guardián. La violencia no desaparece, solo se transforma porque uno se hace responsable del otro, porque uno, en palabras del filósofo, se convierte en "rehén» de la alteridad del otro. Esa prescripción del rostro ajeno, bastante violenta e idealista -y el propio Levinas lo reconoce-, no deja de ser el fundamento de un nuevo humanismo. El pensamiento levinasiano nos pide, después de Auschwitz, mirar -y perdonen la redundancia- al otro de otra manera, anteponiendo al logos el mandamiento de su rostro, fuente de una ética que se halla en la base de todo.

El teatro de Juan Mayorga dista mucho de ser ajeno a tal preocupación. De hecho, el autor afirma varias veces que «la vulnerabilidad del otro es la que me constituye como sujeto moral. Esa tensión la he tenido siempre en mis trabajos» (Mayorga 2014). En Animales nocturnos y Palabra de perro por ejemplo, esta cuestión es esencial. Animales nocturnos pone en escena a cuatro personajes -Hombre Bajo, Mujer Baja, Hombre Alto, Mujer Alta- cuyas relaciones serán trastornadas por el chantaje que se pone en marcha entre dos de ellos. Efectivamente, la primera escena dramatiza el encuentro entre Hombre Alto, un extranjero en situación irregular, y su vecino el Hombre Bajo. Este personaje amenaza al Hombre Alto con denunciarle a las autoridades si se niega a trabar amistad y pasar tiempo con él. Se establece una dinámica amo/ esclavo y se construye una pieza donde se interrogan las relaciones humanas. ¿Estará el hombre a la merced del hombre? ¿Engendrará la vulnerabilidad del otro un comportamiento de solidaridad o de apresamiento hacia mi prójimo? En Palabra de perro -obra libremente inspirada en el Coloquio de los perros de Cervantes- los canes Cipión y Berganza intentan saber por qué tienen la facultad de hablar. Mediante el relato de Berganza, que se rememora los distintos amos 
que tuvo, los dos perros terminan por entender que tienen un origen humano. Fue el tratamiento del hombre el que -metafóricamente- los convirtió en perro, y en particular en lo que concierne a Berganza que antes era un inmigrante clandestino. Animales nocturnos y Palabra de perro abordan la cuestión del otro, encarnado en la figura del extranjero. Además, esta cuestión pasa por un proceso de animalización o deshumanización de los personajes que nos invita a evocar al escritor Franz Kafka:

Mi primer trabajo con animales fue una versión de El coloquio de los perros, de Cervantes. Empezó siendo una versión ortodoxa que se hubiera llamado El coloquio de los perros de Miguel de Cervantes en versión de Juan Mayorga. Pero poco a poco me fui apropiando el material, y hoy se llama Palabra de perro para no engañar al espectador, porque encontrará algo que acaso le parezca demasiado distante de la novela cervantina. En aquel trabajo descubrí el valor poético y el valor político del animal en escena. El valor poético porque el animal rompe el marco y permite una gran libertad al escritor, pero también al actor. [...] Y por otro lado, está el valor político del animal. Aquí uno recoge, de algún modo, la herencia kafkiana: si a un hombre le llamas insecto, acaba siendo un insecto. No en balde en nuestra dolorida España se llamaba perro al converso, al judío o al moro. La animalización del ser humano prepara su maltrato físico. La muerte moral prepara la muerte física. Porque cuesta menos matar a un perro que matar a un ser humano. Si al ser humano lo has convertido previamente en perro, estás preparando su muerte. Y el animal humanizado es el envés de eso que permite hablar, por un lado, sobre cómo los animales nos ven, pero también sobre lo animal que hay en nosotros. (Mayorga 2010b: 6)

La obra de Kafka, reconocida por Juan Mayorga, lo es también, y evidentemente de manera anterior, por Walter Benjamin que dedicó varios escritos al autor checo $^{13}$. Para Benjamin, Kafka es el testigo privilegiado de una modernidad que ha perdido su halo, una modernidad que es pobre en experiencia ${ }^{14}$ y que conduce a los hombres a alejarse los unos de los otros. En este sentido, los personajes kafkianos son personajes marcados por un profunda soledad, pero son también personajes vinculados entre ellos por la culpa mítica, aquella que nos deja culpable ante Dios. Esta culpa mítica, fuente de un gran sentimiento de culpabilidad insondable y misterioso, es también, en la obra de Kafka, la culpa del impotente ante el poder del padre o -para el autor checo, se trata de lo mismo- de la ley (Mate y Mayorga 2008: 94-98). Toda la escritura kafkiana intenta dar cuenta de esa experiencia del hombre impotente ante el mito del poder, una experiencia de la humillación y de la culpa que termina por volverle vulnerable y animalizarle:

La marca de esa culpa antigua hace que el personaje kafkiano viva en el mundo como un extraño: como un extranjero. [...] Y es que, sometido al orden mítico, el ser humano no es nada más que un cuerpo vulnerable. Ése es el descubrimiento final del protagonista de El proceso. Ante la mirada de un observador que no

$13 C f$. la edición reciente de los escritos de Benjamin sobre Kafka (Benjamin 2015).

$14 C f$. el texto «Expérience et pauvreté» (Benjamin 2000b: 364-372). 
le ayuda, siente que sus acusadores le están matando como a un perro. Su animalización -su reducción a ser natural- es la culminación de su "proceso». (Mate y Mayorga 2008: 98-99)

En Animales nocturnos, subyace ese proceso de deshumanización con personajes marcados por un profunda soledad y, por lo menos en lo que concierne al Hombre Alto, por un sentimiento de culpabilidad que lo llevará a la impotencia ante el poder del otro y de la ley. Efectivamente, el Hombre Alto es culpable ante la ley según su vecino, pero se trata de una ley a la cual nunca se alude de manera precisa, una ley que nunca se menciona detalladamente y que es, de alguna manera, anonimizada por la manera como la designa el Hombre $B a j o^{15}$. El misterio de la ley o del poder basta para someter al Hombre Alto y reducirlo a su condición de cuerpo vulnerable, convertido al final de la pieza en verdadero pelele al servicio no solo de su vecino, sino también de la Mujer Baja ${ }^{16}$.

\section{A modo de conclusión}

La ley y el poder parecen ser datos indispensables para la comprensión de un fenómeno tan complejo como lo es la violencia. La ambigüedad de la ley y del poder en relación con la violencia es reveladora. Pretenden proteger de la violencia $y$, sin embargo, no parecen nunca lograr prescindir de ella. Parecen incluso fundarse en ella. Vimos que para Levinas, la prescripción ética del rostro ajeno no es incompatible con la instauración de una ley y un orden político justo. Para Kafka, en cambio, no se puede esperar nada del poder o de la ley, porque son mitos que ocultan el sometimiento y la animalización del hombre. En este sentido, destaca en el teatro de Juan Mayorga la fuerte crítica a las instituciones, pues vemos que desde ellas emana un componente social violentador contra ciertos sectores de la población. Sin la presencia de la ley de inmigración no sería posible la relación de sumisión en Animales nocturnos. En Himmelweg, no habría necesidad de representar un contexto de paz en el campo si las naciones hubieran hecho un trabajo más a fondo para investigar la veracidad de Theresienstadt. Desviamos aquí hacia una dimensión política y social de la violencia que no tenemos tiempo de desarrollar. Sin embargo, es de notar que todos los aspectos de la violencia en la producción dramática de Mayorga están estrechamente vinculados. Cada obra ofrece varias caras a la hora de ser analizada y hace eco con numerosas voces filósoficas. Como lo hemos visto, el prisma benjaminiano es solamente la punta del iceberg y queda mucho trabajo aún para desvelar cuanto nos puede decir la dramaturgia mayorguiana sobre nuestra modernidad.

15 Este personaje habla de «ley de inmigración» o «ley tres siete cinco cuatro».

16 La pieza termina con un baile entre el Hombre Alto y la Mujer Alta, después de que el Hombre Bajo lo ha exigido. 


\section{Bibliografía}

Arendt H., 1972, Les origines du totalitarisme. 3, Le système totalitaire, Paris, Seuil.

Arendt H., 2002, Eichmann à Jérusalem. Rapport sur la banalité du mal, Paris, Gallimard.

Benjamin W., 1971, Poésie et révolution, Paris, Lettres Nouvelles.

Benjamin W., 2000a, Euvres I, Paris, Gallimard.

Benjamin W., 2000b, Euvres II, Paris, Gallimard.

Benjamin W., 2015, Sur Kafka, Caen, Nous.

Chalier C., 2011, «Levinas Emmanuel, 1906-1995», in: Michela Marzano (dir.), Dictionnaire de la violence, Paris, PUF.

Collomb M., 2011, «Benjamin Walter, 1892-1940», in: Michela Marzano (dir.), Dictionnaire de la violence, Paris, PUF.

Cordone G., 2011, «La tortuga de Darwin de Juan Mayorga. Hacia une lectura benjaminiana de la historia», Estreno, 2, p. 101-114.

Jonas H., 1994, Le Concept de Dieu après Auschwitz, Paris, Payot \& Rivages.

Jonas H., 2013, Le principe responsabilité, Paris, Flammarion.

Löwy M., 2003, «Progrès et catastrophe. La conception de l'histoire de Walter Benjamin», Historein, 4, p. 199-205.

March Tortajada R., 2014, Memoria y desmemoria, pensamiento y poética en la dramaturgia de Juan Mayorga, Thèse de doctorat, Universitat de València, http://mobiroderic.uv.es/handle/10550/40874 [Consulta: 7/01/2016].

Mate R., Mayorga J., 2008, “"Los avisadores del fuego": Rosenzweig, Benjamin y Kafka», in: Mate R. (dir.), La filosofía después del Holocausto, Barcelona, Riopiedras.

Mayorga J., 2003, Revolución conservadora y conservación revoluconaria. Política $y$ memoria en Walter Benjamin, México, Anthropos.

Mayorga J., 2004, «Job», in: Bárcena F., Chalier C., Levinas E., Lois J., Mardones J. M., Mayorga J., La autoridad del sufrimiento. Silencio de Dios y preguntas del hombre, México, Anthropos.

Mayorga J., 2010a, «Elipses de Benjamin», Constelaciones. Revista de teoría crítica, 2, p. 372-374.

Mayorga J., 2010b, «Conversación con Juan Mayorga», Pausa, 32, http://www. salabeckett.cat/fitxers/pauses/pausa-32/conver.-con-juan-mayorga.-ruthvilar-i-salva-artesero [Consulta: 7/01/2016].

Mayorga J., 2014, «Hay que desobedecer al espectador», La Vanguardia, http://www.lavanguardia.com/libros/20140623/54410309275/juan-mayorgadesobedecer-al-espectador.html [Consulta: 7/01/2016].

Molanes Rial M., 2014, "Walter Benjamin en la poética dramática de Juan Mayorga», $452^{\circ} \mathrm{F}$. Revista electrónica de teoría de la literatura y literatura comparada, 11, p. 161-177. 
Revault D’Allones M., 2011, «Mal. Banalité du mal», in: Michela Marzano (dir.), Dictionnaire de la violence, Paris, PUF.

Ricœur P., 2004, Le mal. Un défi à la philosophie et à la théologie, Genève, Labor et Fides.

Ricœur P., 2005, «Le scandale du mal», Esprit, juillet, p. 104-111.

Spooner C., 2013, Le théâtre de Juan Mayorga: de la scène au monde à travers le prisme du langage, Thèse de doctorat, Université Toulouse Le Mirail - Toulouse II/Universitat Autònoma de Barcelona, https://tel.archivesouvertes.fr/tel-00975193/document [Consulta: 7/01/2016].

Theis R., 2000, «Dieu éclaté. Hans Jonas et les dimensions d'une théologie philosophique après Auschwitz», Revue Philosophique de Louvain, 98, 2, p. 341-357. 